Odessa National Maritime Academy, Odessa, 4, Didrikhsona str., Odessa, Ukraine e-mail: zaichkopa@gmail.com

\title{
RELATIVISTIC SPECTROSCOPY OF HEAVY RYDBERG ATOMIC SYSTEMS IN A BLACK-BODY RADIATION FIELD
}

We present the results of studying the spectroscopic characteristics of heavy Rydberg atomic systems in a blackbody (thermal) radiation field. As theoretical approach we apply the combined generalized relativistic energy approach and relativistic many-body perturbation theory with ab initio Dirac zeroth approximation. There are presented the calculational data for the thermal black-body radiation ionization characteristics of the alkali Rydberg atoms, in particular, the sodium in Rydberg states with principal quantum number $n=10-100$ and ytterbium ion. Application of theory to computing the spectral parameters of studied atomic systems have demonstrated physically reasonable agreement between the theoretical and experimental data. The accuracy of the theoretical data is provided by a correctness of the corresponding relativistic wave functions and accounting for the exchange-correlation effects.

\section{Introduction}

At the present time, the study of Rydberg atoms (molecules) is definitely one of the most popular and very interesting directions of modern quantum physics and chemistry, atomic optics and spectroscopy. The huge relevance of the investigation of the energy and spectral properties of the Rydberg atoms (molecules) is, of course, due to the standard requirements for spectroscopic information of a number of applications and related physical disciplines, which include physics and chemistry of laboratory, astrophysical plasma, astrophysics and radioastronomy, atomic and molecular optics and spectroscopy, laser physics and quantum electronics and many others [1-94]). From the other side, the experiments with Rydberg atoms had very soon resulted in the discovery of an important ionization mechanism, provided by unique features of the Rydberg atoms.

Relatively new topic of the modern theory is connected with consistent treating the Rydberg atoms in a field of the Blackbody radiation (BBR). It should be noted that the BBR is one of the essential factors affecting the Rydberg states in atoms [1]. The account for the ac Stark shift, fast redistribution of the levels' population and photoionization provided by the environmental BBR became of a great importance for successfully handling atoms in their Rydberg states.
The vast majority of existing papers on the description of Rydberg atoms in the thermal radiation field (c.g. [1-32]) are based on the Coulomb hydrogen-like approximation, different versions of the quantum defect method, classical and quasiclassical model approaches, the model and pseudo - potential methods. The authors of the papers [3-10] applied the Coulomb approximation, quantum defect formalism, different versions of the model and pseudo-potential method etc (as a rule, the non-relativistic versions are used) to determine the spectral and radiative properties of different Rydberg atoms and ions.

It should be noted separately the cycles of theoretical and experimental works by RyabtsevBeterov et al [2,3], as well as theoretical works of Dyachkov-Pankratov and others (c.g.[1-10]), in which the advanced versions of a quasi-classical approach to the calculation of radiation amplitudes, oscillator strengths, and cross-sections for the Rydberg atoms in the BBR radiation field were actually developed. In the papers [1-3,710] the authors present the calculational data on the ionization rates for Rydberg atoms of alkali elements (lithium, sodium, potassium, caesium) by a BBR radiation field. The calculations were carried out for the $\mathrm{nS}, \mathrm{nP}$, and $\mathrm{nD}$ states in the wide range of principal quantum numbers and temperatures. The above theoretical works and relevant models were substantially based on non-relativistic approximation. 
At the same time one should note that for heavy Rydberg atoms (both in the free state and in an external electromagnetic field) it is fundamentally important to accurately account for both relativistic and exchange-correlation effects.

The quality and consistency of accounting for these effects also determine the accuracy of description of the energy and spectroscopic parameters of the heavy Rydberg atoms, including these atoms in a thermal radiation field.

Naturally, the standard methods of the theoretical atomic physics, including the HartreeFock and Dirac-Fock approximations should be used in order to determine the thermal ionization characteristics of neutral and Rydberg atoms [2].

One could note that the correct treating of the heavy Rydberg atoms parameters in an external electromagnetic field, including the BBR field, requires using strictly relativistic models. In a case of multielectron atomic systems it is necessary to account for thee exchange-correlation corrections.

Among the fundamentally important exchange-correlation effects for essentially manyelectron systems, one should single out such effects as polarization interaction and screening, continuum pressure, the non-Coulomb grouping of levels in the heavy Rydberg atoms spectra etc. It should be noted that these effects are not correctly considered, for example, within simplified Coulomb approximation or quantum defect models (c.g.[11-20]). Their account requires using very consistent methods.

We present the results of studying the spectroscopic characteristics of heavy Rydberg atomic systems in a black-body (thermal) radiation field.

As theoretical approach we apply the combined generalized relativistic energy approach and relativistic many-body perturbation theory with ab anitio Dirac zeroth approximation.

\section{Atom in a Black-body radiation field: Theoretical aspects}

From the physical viewpoint, a qualitative picture of the BBR Rydberg atoms ionization is easily understandable. Even for temperatures of order $\mathrm{T}=10^{4} \mathrm{~K}$, the frequency of a greater part of the BBR photons $\omega$ does not exceed 0.1 a.u. Usually, it is enough to use a single- electron approximation for calculating the ionization cross section $\sigma_{n l}(\omega)$.

The latter appears in a product with the Planck's distribution for the thermal photon number density:

$$
\rho(w, T)=\frac{\omega^{2}}{\pi^{2} c^{3}[\exp (\omega / k T)-1]},
$$

where $k=3.1668 \times 10^{-6}$ a.u., $\mathrm{K}^{-1}$ is the Boltzmann constant, $c=137.036$ a.u. is the speed of light. Ionization rate of a bound state $n l$ results in the integral over the Blackbody radiation frequencies:

$$
P_{h b}(T)=c \int_{\left|E_{i n}\right|}^{\infty} \sigma_{h}(\omega) \rho(\omega, T) d \omega .
$$

The ionization cross-section from a bound state with a principal quantum number $n$ and orbital quantum number $l$ by photons with frequency $\omega$ is as follows:

$$
\begin{aligned}
\sigma_{l h}(\omega) & =\frac{4 \pi^{2} \omega}{3 c(2 l+1)}\left[M_{h \rightarrow E-1}^{2}+\right. \\
& \left.+(l+1) M_{l h \rightarrow E+1}^{2}\right],
\end{aligned}
$$

where the radial matrix element of the ionization transition from the bound state with the radial wave function $R_{n l}(r)$ to continuum state with the wave function $R_{E l}(r)$ normalized to the delta function of energy.

The corresponding radial matrix elements are written by the standard way. Other details can be found in Refs. [9-16].

\section{Relativistic perturbation theory and energy approach}

We apply a generalized energy approach [920] and relativistic perturbation theory with the zeroth approximation [21-32] to computing the Rydberg atoms ionization parameters. According to Ref. [11,22], the RMBPT zeroth order Hamiltonian of the Rydberg atomic system is as follows:

$$
\begin{aligned}
& H_{0}=\sum_{i}\left\{\alpha c p_{i}-\beta m c^{2}+\left[-Z / r_{i}+\right.\right. \\
& \left.U_{M F}\left(r_{i} \mid b\right)+V_{X C}\left(r_{i}\right)\right]
\end{aligned}
$$


where $c$ is the velocity of light, $a_{i}, a_{j}-$ the Dirac matrices, $w_{i j}$-the transition frequency, $Z$ is a charge of atomic nucleus. The general potential in (4) includes self-consistent Coulomblike mean-field potential $U_{F}\left(r_{i} \mid b\right)$, ab ibitio one-particle exchange-correlation (relativistic generalized exchange Kohn-Sham potential plus generalized correlation Lundqvist-Gunnarsson potential) $V_{E}\left(r_{i} \mid b\right)$ with the gauge calibrated parameter $b$ (it is determined within special relativistic procedure on the basis of relativistic energy approach; c.g. [21-32]).

The perturbation operator is as follows:

$$
\begin{gathered}
H^{P T}=\sum_{i>j} \exp \left(i \omega_{i j} r_{i j}\right) \cdot \frac{\left(1-\alpha_{i} \alpha_{j}\right)}{r_{i j}}- \\
\sum_{i}\left[U_{M F}\left(r_{i}\right)+V_{X C}\left(r_{i} \mid b\right)\right]
\end{gathered}
$$

The multielectron interelectron exchangecorrelation effects (the core polarization and screening effects, continuum pressure etc) are taken into consideration as the RMBPT second and higher orders contributions. The details of calculation of the corresponding matrix elements of the polarization and screening interelectron interaction potentials are described in Refs. [9,22,33-38].

In relativistic theory radiation decay probability (ionization cross-section etc) is connected with the imaginary part of electron energy shift. The total energy shift of the state is usually presented in the form: $D E=\operatorname{ReDE}+\mathrm{i} G / 2$, where $\mathrm{G}$ is interpreted as the level width, and a decay probability $\mathrm{P}=\mathrm{G}$. The imaginary part of electron energy shift is defined in the PT lowest order as:

$$
\text { m } \Delta E(B)=-\frac{e^{2}}{4 \pi} \sum_{\substack{\alpha>n>f \\[<<n \leq f]}}^{\left|\omega_{\alpha n \alpha n}\right|},
$$

where $(a>n>f)$ for electron and $(a<n<f)$ for vacancy. The matrix element is determined as follows:

$$
\begin{aligned}
V_{i j k l}^{|\omega|}=\iint & d r_{1} d r_{2} \Psi_{i}^{*}\left(r_{1}\right) \Psi_{j}^{*}\left(r_{2}\right) \frac{\sin |\omega| r_{12}}{r_{12}}(1- \\
& \left.-\alpha_{1} \alpha_{2}\right) \Psi_{k}^{*}\left(r_{2}\right) \Psi_{l}^{*}\left(r_{1}\right)
\end{aligned}
$$

Their detailed description of the matrix elements and procedure for their computing is presented in Refs. [16-20]. The relativistic wave functions are calculated by solution of the Dirac equation with the potential, which includes the Dirac-Fock consistent field potential and additionally polarization potential [22].

The total ionization rate of the Rydberg atomic system in the BBR radiation field is usually determined as the sum of direct BBR ionization rate of the initially excited state, the ionization (field ionization) rate of highly excited states, which are populated from the initial Rydberg state via absorption of the BBR photons, the rate of direct BBR-induced ionization of atoms from the neighbouring Rydberg states and the rate of field ionization of high-lying Rydberg states (with populating through so called twostep process via the BBR photons absorption).

The total width of the Rydberg state (naturally isolated from all external electromagnetic fields except BBR one) consists, apparently, of natural, spontaneous radiation width $\tilde{A}_{c h}^{p}$ and BBR-induced (thermal) width $\tilde{\mathrm{A}}_{b}^{B B R}$ :

$$
\tilde{\mathrm{A}}_{h}^{\text {tot }}=\tilde{\mathrm{A}}_{h}^{p}+\tilde{\mathrm{A}}_{h}^{B B R}(T) .
$$

Accordingly, the effective lifetime of the Rydberg state is inversely proportional to the total decay rate as a result of spontaneous transitions and transitions induced by the BBR radiation:

$$
\frac{1}{\tau_{\text {eff }}}=\tilde{\mathrm{A}}_{0}+\tilde{\mathrm{A}}_{\mathrm{BBR}}=\frac{1}{\tau_{0}}+\frac{1}{\tau_{B B R}}
$$

The detailed procedures of calculation of the radial and angular integrals (amplitudes) in the matrix elements are described in Refs. [920,22,38-41]. All calculations are performed on the basis of the numeral code Superatom-ISAN (version 93).

\section{Results and conclusions}

In Table 1 we present our theoretical data on the effective lifetime of the sodium $\mathrm{nP}, \mathrm{nD}$ Rydberg states and for comparison some theoretical data by Beterov et al [2,3] for temperatures $\mathrm{T}=300,600 \mathrm{~K}$. In Table 2 we present our theoretical data on the effective lifetime of the sodium $\mathrm{nP}, \mathrm{nD}$ Rydberg states for temperatures $\mathrm{T}=300$ 
and $600 \mathrm{~K}$. Obviously, the accuracy of the theoretical data is provided by a correctness of the corresponding relativistic wave functions and accounting for the exchange-correlation effects.

Table 1.

Effective lifetime ( $\mu s)$ of the nP Rydberg states in the sodium spectrum for the temperature $T=300$ : $[2]$ - theory by Beterov et al and this work.

\begin{tabular}{|c|c|c|}
\hline \multirow{3}{*}{$\mathrm{n}$} & $\underline{\mathrm{T}=300 \mathrm{~K}}$ & $\underline{\mathrm{T}=300}$ \\
& $\mathrm{P}_{1 / 2}$ & $\underline{\mathrm{K}}$ \\
& $\mathrm{P}_{3 / 2}$ & $\mathrm{P}_{1 / 2}$ \\
& Ref. & $\mathrm{P}_{3 / 2}$ \\
& {$[2]$} & This \\
work \\
\hline 10 & 4.80 & 4.84 \\
& 4.76 & 4.81 \\
\hline 20 & 20.99 & 21.06 \\
& 20.89 & 20.96 \\
\hline 30 & 48.71 & 48.84 \\
& 48.56 & 48.70 \\
\hline
\end{tabular}

Effective lifetime ( $\mu$ s) of the $\mathrm{nP}, \mathrm{nD}$ Rydberg states in the sodium spectrum for the temperatures $T=300,600 \mathrm{~K}$ (this work).

\begin{tabular}{|c|c|c|c|}
\hline \multirow{2}{*}{$\mathrm{n}$} & $\frac{\mathrm{T}=600}{\underline{\mathrm{K}}}$ & $\frac{\mathrm{T}=300 \mathrm{~K}}{\mathrm{P}_{1 / 2}}$ & $\underline{\underline{\mathrm{T}}=600}$ \\
& $\begin{array}{c}\mathrm{P}_{3 / 2} \\
\text { This } \\
\text { work }\end{array}$ & $\begin{array}{c}\mathrm{D}_{5 / 2} \\
\text { This work }\end{array}$ & $\begin{array}{c}\mathrm{D}_{5 / 2} \\
\text { This } \\
\text { work }\end{array}$ \\
\hline 10 & 2.84 & 0.913 & 0.837 \\
& 2.83 & 0.914 & 0.838 \\
\hline 20 & 11.42 & 6.263 & 5.164 \\
& 11.38 & 6.266 & 5.167 \\
\hline 30 & 26.03 & 18.602 & 14.281 \\
& 25.97 & 18.609 & 14.285 \\
\hline
\end{tabular}

In conclusion we also present our result of computing the relative blackbody radiative shift (in $10^{-14}$ ) for singly ionized $\mathrm{Yb}$ : $\beta=--0.097$.
The similar $\beta$ values are obtained using thirdorder relativistic many-body calculations [4] $\beta=-0.0983$ and ab initio method [5]: $\beta=-0.094$. In these calculations different methods are used to compute matrix elements and different orbital basises are used. The details of this problem will be presented in a separate paper.

\section{References}

1. Beloy K., Safronova U., Derevianko, A. High-accuracy calculation of the blackbody radiation shift in the $133 \mathrm{Cs}$ primary frequency standard. Phys. Rev. Lett. 2006, 97, 040801.

2. Beterov, I.I., Ryabtsev, I., Tretyakov D., Entin, V. Quasiclassical calculations of blackbody-radiation-induce depopulation rates and effective lifetimes of Rydberg $n S, n P$, and $n D$ alkali-metal atoms with $n \sim 80$. Phys Rev A. 2009, 79, 052504.

3. Beterov I.I., Ionization of Rydberg atoms by blackbody radiation/ Beterov I.I., TretyakovD.V., Ryabtsev I.I., Entin V.M., Ekers A., Bezuglov N.N.//New J. Phys.-2009.-Vol.11.-P.013052

4. Safronova U., Safronova M. Third-order relativistic many-body calculations of energies, transition rates, hyperfine constants, blackbody radiation shift in ${ }^{171} \mathrm{Yb}^{+}$. Phys. Rev. A. 2009, 79, 022512.

5. Angstmann, E., Dzuba, V., Flambaum, V. Frequency shift of hyperfine transitions due to blackbody radiation. Phys. Rev. A. 2006, 74, 023405.

6. Gallagher T.F., Cooke W.E. Interactions of Blackbody Radiation with atoms. Phys. Rev. Lett. 1979, 42, 835-839.

7. Lehman G. W. Rate of ionization of $\mathrm{H}$ and $\mathrm{Na}$ Rydberg atoms by black-body radiation. J. Phys. B: At. Mol. Phys. 1983, 16, 21452156.

8. D'yachkov L., Pankratov P. On the use of the semiclassical approximation for the calculation of oscillator strengths and photoionization cross sections. J. Phys. B: At. Mol. Opt. Phys. 1994, 27, 461-468.

9. Svinarenko A.A., Khetselius O.Yu., Buyadzhi V.V., Florko T.A., Zaichko P.A., Ponomarenko E.L., Spectroscopy of Rydberg 
atoms in a Black-body radiation field: Relativistic theory of excitation and ionization. J. Phys.: Conf. Ser. 2014, 548, 012048.

10. Svinarenko A.A., Khetselius O.Yu., Buyadzhi V., Kvasikova A., Zaichko P. Spectroscopy of Rydberg atoms in a Black-body radiation field: Relativistic theory of excitation and ionization. Photoelectronics. 2014, 23, 147-151.

11. Glushkov, A.V., Ternovsky, V.B., Buyadzhi, V., Tsudik, A., Zaichko, P. Relativistic approach to calcuation of ionization characteristics for rydberg alkali atom in a black-body radiation field. Sensor Electr. and Microsyst. Techn. 2019, 16(3), 69-77.

12. Glushkov, A.V. Relativistic Quantum theory. Quantum mechanics of atomic systems. Astroprint: Odessa, 2008.

13. Glushkov, A.V., Khetselius, O.Yu., Svinarenko, A.A., Buyadzhi, V.V., Spectroscopy of autoionization states of heavy atoms and multiply charged ions. TEC: Odessa, 2015.

14. Glushkov, A.V., Svinarenko, A.A., Ternovsky, V.B., Smirnov, A.V., Zaichko, P.A., Spectroscopy of the complex autoionization resonances in spectrum of helium: Test and new spectral data. Photoelectronics. 2015, 24, 94-102.

15. Glushkov A.V., Ternovsky V.B., Buyadzhi V., Zaichko P., Nikola L. Advanced relativistic energy approach to radiation decay processes in atomic systems. Photoelectr. 2015, $24,11-22$.

16. Ivanov, L.N.; Ivanova, E.P. Method of Sturm orbitals in calculation of physical characteristics of radiation from atoms and ions. JETP. 1996, 83, 258-266.

17. Glushkov, A.; Ivanov, L.; Ivanova, E.P. Autoionization Phenomena in Atoms. Moscow Univ. Press, Moscow, 1986, 58.

18. Glushkov, A.; Ivanov, L. Radiation decay of atomic states: atomic residue polarization and gauge noninvariant contributions. Phys. Lett.A 1992, 170, 33.

19. Glushkov A.V.; Ivanov, L.N. DC strongfield Stark effect: consistent quantum-mechanical approach. J. Phys. B: At. Mol. Opt. Phys. 1993, 26, L379-386.

20. Glushkov A.V., Multiphoton spectroscopy of atoms and nuclei in a laser field: Relativistic energy approach and radiation atomic lines moments method. Adv. in Quantum Chem. 2019, 78, 253-285.

21. Glushkov, A.V.; Khetselius, O.Yu.; Svinarenko A. Theoretical spectroscopy of autoionization resonances in spectra of lanthanides atoms. Phys. Scripta. 2013, T153, 014029.

22. Glushkov, A.V. Relativistic and correlation effects in spectra of atomic systems. Astroprint: Odessa, 2006.

23. Khetselius, O.Yu. Hyperfine structure of atomic spectra. Astroprint: Odessa, 2008.

24. Khetselius, O.Yu. Relativistic perturbation theory calculation of the hyperfine structure parameters for some heavy-element isotopes. Int. Journ. Quant.Chem. 2009, 109, 3330-3335.

25. Khetselius, O. Relativistic calculation of the hyperfine structure parameters for heavy elements and laser detection of the heavy isotopes. Phys.Scr. 2009, T135, 014023

26. Khetselius, O.Yu. Optimized relativistic many-body perturbation theory calculation of wavelengths and oscillator strengths for $\mathrm{Li}$ like multicharged ions. Adv. Quant. Chem. 2019, 78, 223-251.

27. Khetselius, O.Yu., Glushkov, A.V., Dubrovskaya, Yu.V., Chernyakova, Yu., Ignatenko, A.V., Serga, I., Vitavetskaya, L. Relativistic quantum chemistry and spectroscopy of exotic atomic systems with accounting for strong interaction effects. In: Concepts, Methods and Applications of Quantum Systems in Chemistry and Physics. Springer, Cham, 2018, 31, 71-91.

28. Khetselius, O.Yu. Quantum structure of electroweak interaction in heavy finite Fermi-systems. Astroprint: Odessa, 2011.

29. Glushkov, A., Vitavetskaya, L. Accurate QED perturbation theory calculation of the structure of heavy and superheavy element atoms and multicharged ions with the account of nuclear size effect and QED corrections. Herald of Uzhgorod Univ. 2000, 8(2), 321-324.

30. Svinarenko, A., Glushkov, A, Khetselius, O., Ternovsky, V., Dubrovskaya Y., Kuznetsova 
A., Buyadzhi V. Theoretical spectroscopy of rare-earth elements: spectra and autoionization resonances. Rare Earth Element, Ed. J. Orjuela (InTech) 2017, pp 83-104.

31. Glushkov, A.V., Khetselius, O.Yu., Svinarenko A.A., Buyadzhi, V.V., Ternovsky, V.B, Kuznetsova, A., Bashkarev, P Relativistic perturbation theory formalism to computing spectra and radiation characteristics: application to heavy element. Recent Studies in Perturbation Theory, ed. D. Uzunov (InTech) 2017, 131-150.

32. Glushkov A.V., Khetselius O.Yu., Svinarenko A.A., Buyadzhi V.V., Methods of computational mathematics and mathematical physics. P.1. TES: Odessa, 2015.

33. Dubrovskaya, Yu., Khetselius, O.Yu., Vitavetskaya, L., Ternovsky, V., Serga, I. Quantum chemistry and spectroscopy of pionic atomic systems with accounting for relativistic, radiative, and strong interaction effects. Adv. in Quantum Chem. 2019, Vol.78, pp 193-222.

34. Bystryantseva A., Khetselius O.Yu., Dubrovskaya Yu., Vitavetskaya L.A., Berestenko A.G. Relativistic theory of spectra of heavy pionic atomic systems with account of strong pion-nuclear interaction effects: ${ }^{93} \mathrm{Nb},{ }^{173} \mathrm{Yb},{ }^{181} \mathrm{Ta},{ }^{197} \mathrm{Au}$. Photoelectronics. 2016, 25, 56-61.

35. Khetselius, O., Glushkov, A., Gurskaya, M., Kuznetsova, A., Dubrovskaya Yu., Serga I., Vitavetskaya L. Computational modelling parity nonconservation and elec- troweak interaction effects in heavy atomic systems within the nuclear-relativistic many-body perturbation theory. J. Phys.: Conf. Ser. 2017, 905(1), 012029.

36. Khetselius O., Gurnitskaya E. Sensing the electric and magnetic moments of a nucleus in the N-like ion of Bi. Sensor Electr. and Microsyst. Tech. 2006, N3, 35

37. Khetselius, O.Yu., Lopatkin Yu.M., Dubrovskaya, Yu.V, Svinarenko A.A. Sensing hyperfine-structure, electroweak interaction and parity non-conservation effect in heavy atoms and nuclei: New nuclear-QED approach. Sensor Electr. and Microsyst. Techn. 2010, 7(2), 11-19.

38. Glushkov A.V., Malinovskaya S.V., Dubrovskaya Yu.V., Sensing the atomic chemical composition effect on the beta decay probabilities. Sensor Electr. and Microsyst. Techn. 2005, 2(1), 16-20.

39. Florko, T.A.; Tkach, T.B.; Ambrosov, S.V.; Svinarenko, A.A. Collisional shift of the heavy atoms hyperfine lines in an atmosphere of the inert gas. J. Phys.: Conf. Ser. 2012, 397, 012037.

40. Buyadzhi V.; Chernyakova Yu.; Smirnov A; Tkach T. Electron-collisional spectroscopy of atoms and ions in plasma: Be-like ions. Photoelectronics. 2016, 25, 97-101

41. Buyadzhi, V.V.; Chernyakova, Yu.G.; Antoshkina, O.; Tkach, T. Spectroscopy of multicharged ions in plasmas: Oscillator strengths of Be-like ion Fe. Photoelectronics. 2017, 26, 94-102. 
PACS: 31.15.ac, 31.15.ag, 31.15.aj

A. V. Tsudik, A. A. Kuznetsova, P. A. Zaichko, V. F. Mansarliysky

\title{
RELATIVISTIC SPECTROSCOPY OF HEAVY RYDBERG ATOMIC SYSTEMS IN A BLACK-BODY RADIATION FIELD
}

\begin{abstract}
Summary. We present the results of studying the spectroscopic characteristics of heavy Rydberg atomic systems in a black-body (thermal) radiation field. As theoretical approach we apply the combined generalized relativistic energy approach and relativistic many-body perturbation theory with ab initio Dirac zeroth approximation. There are presented the calculational data for the thermal black-body radiation ionization characteristics of the alkali Rydberg atoms, in particular, the sodium in Rydberg states with principal quantum number $n=10-100$ and ytterbium ion. Application of theory to computing the spectral parameters of studied atomic systems have demonstrated physically reasonable agreement between the theoretical and experimental data. The accuracy of the theoretical data is provided by a correctness of the corresponding relativistic wave functions and accounting for the exchange-correlation effects.
\end{abstract}

Key words: Rydberg heavy atoms, relativistic theory, black-body radiation field.

PACS: 31.15.ac, 31.15.ag, 31.15.aj

А. В. Цудик, А. А. Кузнецова, П. А. Заичко, В. Ф. Мансарлийский

\section{РЕЛЯТИВИСТСКАЯ СПЕКТРОСКОПИЯ ТЯЖЕЛЫХ РИДБЕРГОВСКИХ АТОМНЫХ СИСТЕМ В ПОЛЕ ИЗЛУЧЕНИЯ ЧЕРНОГО ТЕЛА}

Резюме. Представлены результаты изучения спектроскопических характеристик тяжелых ридберговских атомных систем в поле чернотел(теплового) излучения. В качестве теоретического подхода мы применяем комбинированный релятивистский энергетический подход и релятивистскую многочастичную теорию возмущений с оптимизированныи дираковским нулевым приближением. Представлены результаты расчета спектроскопических характеристик щелочных ридберговских атомов в поле теплового излучения черного тела, в частности, натрия в ридберговских состояниях с главным квантовым числом $\mathrm{n}=20-100$ и иона иттербия. Применение теории к вычислению спектральных параметров исследуемых атомных систем продемонстрировало физически разумное согласие между теоретическими и экспериментальными данными. Точность теоретических данных обеспечивается корректностью вычисления соответствующих релятивистских волновых функций и полнотой учета обменно-корреляционных эффектов.

Ключевые слова: ридберговские тяжелые атомы, релятивистская теория, тепловое излучение.

PACS: 31.15.ac, 31.15.ag, 31.15.aj

\author{
А. В. Цудік, Г. О. Кузнецова, П. А. Заічко, В. Ф. Мансарлійський
}

\section{РЕЛЯТИВІСТСЬКА СПЕКТРОСКОПІЯ ВАЖКИХ РІДБЕРГІВСЬКИХ АТОМНИХ СИСТЕМ В ПОЛІ ВИПРОМІНЮВАННЯ ЧОРНОГО ТІЛА}

Резюме. Представлені результати вивчення спектроскопічних характеристик важких рідбергівських атомних систем в полі чорнотільного (теплового) випромінювання. В якості теоретичного підходу ми застосовуємо комбінований релятивістський енергетичний підхід і ре- 
лятивістську багаточастинкову теорію збурень з оптимізованим діраківським нульовим наближенням. Представлені результати розрахунку спектроскопічних характеристик лужних рідбергівських атомів в полі теплового випромінювання, зокрема, натрію в рідбергівських станах 3 головним квантовим числом $\mathrm{n}=20-100$ та іону ітербію. Застосування теорії до обчислення спектральних параметрів досліджуваних атомних систем продемонструвало фізично розумну згоду між теоретичними і експериментальними даними. Точність теоретичних даних забезпечується коректністю обчислення відповідних релятивістських хвильових функцій і повнотою обліку обмінно-кореляційних ефектів.

Ключові слова: рідбергівські важкі атоми, релятивістська теорія, теплове випромінювання. 